\title{
nombalina
}

(8)

\section{Política e história nos Epigramas de Marcial}
Autor(es):
Pimentel, Cristina de Sousa
Instituto de Estudos Clássicos, Centro de Estudos Clássicos e
Publicado por: Humanísticos; Departamento de Estudos Clássicos, Centro de Estudos Clássicos

\author{
URL \\ persistente: \\ URI:http://hdl.handle.net/10316.2/34628 \\ DOI: \\ DOI:http://dx.doi.org/10.14195/978-989-26-0901-0_2
}

Accessed : $\quad$ 26-Apr-2023 11:22:06

A navegação consulta e descarregamento dos títulos inseridos nas Bibliotecas Digitais UC Digitalis, UC Pombalina e UC Impactum, pressupõem a aceitação plena e sem reservas dos Termos e Condições de Uso destas Bibliotecas Digitais, disponíveis em https://digitalis.uc.pt/pt-pt/termos.

Conforme exposto nos referidos Termos e Condições de Uso, o descarregamento de títulos de acesso restrito requer uma licença válida de autorização devendo o utilizador aceder ao(s) documento(s) a partir de um endereço de IP da instituição detentora da supramencionada licença.

Ao utilizador é apenas permitido o descarregamento para uso pessoal, pelo que o emprego do(s) título(s) descarregado(s) para outro fim, designadamente comercial, carece de autorização do respetivo autor ou editor da obra.

Na medida em que todas as obras da UC Digitalis se encontram protegidas pelo Código do Direito de Autor e Direitos Conexos e demais legislação aplicável, toda a cópia, parcial ou total, deste documento, nos casos em que é legalmente admitida, deverá conter ou fazer-se acompanhar por este aviso.

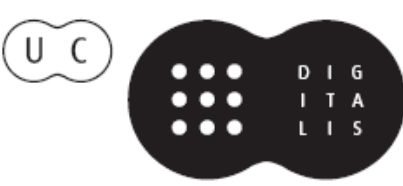




\section{Toto notus in orbe Martialis}

\section{Celebração de Marcial \\ 1900 anos após a sua morte}

Coordenação

Cristina de Sousa Pimentel

Delfim F. Leão

José Luís L. Brandão

Instituto de Estudos Clássicos

Centro de Estudos Clássicos e Humanísticos

UNIVERSIDADE DE COIMBRA
Departamentō de Estudos Clássicos Centro de Estudos Clássicos UNIVERSIDADE DE LISBOA 


\title{
POLÍTICA E HISTÓRIA NOS EPIGRAMAS DE MARCIAL
}

\author{
MARIA CRISTINA DE CASTRO-MAIA DE SOUSA PIMENTEL \\ Faculdade de Letras de Lisboa
}

\begin{abstract}
Résumé: Dans l'article présent, nous analysons la stratégie d'adulation contenue dans les Epigrammes de Martial, choisissant, comme objet d'étude et de commentaire, les poèmes dans lesquels l'éloge s'adresse à quelques personnalités d'entre celles qui étaient les plus proches de l'Empereur et qui, ayant le privilège de partager son intimité, se trouvaient en position de le protéger et de recommander sa poésie auprès de l'instance suprême du pouvoir.

La réflexion survient, spécifiquement, sur les techniques littéraires et les recours stylistiques que le poète utilise pour aduler les liberti de Domitien (Parthenius, Euphemus, Sigerus, Sextus, Entellus), son puer delicatus Earinus et les délateurs Regulus, Latinus et Crispinus. L'analyse révèle, cependant, comme, dans toutes les circonstances, l'adulatio vise, indubitablement, le princeps, seigneur absolu de Rome.
\end{abstract}

Uma das áreas temáticas que tem suscitado mais estudos sobre a obra de Marcial é, sem dúvida, a do culto dos imperadores, suas formas e objectivos. Entre as questões abordadas, analisa-se o culto imperial, desde as origens romanas com Augusto e os seus antecessores helenísticos, até à sua aplicação na figura do último princeps da dinastia flávia; estudam-se as formas que esse culto assumiu e desenham-se as coordenadas da teologia do poder imperial, documentando-as nos Epigramas. Sem perder de vista a análise histórica do principado e a avaliação do merecimento ou demérito de Domiciano, coloca-se uma outra questão: Marcial adulou porque quis adular, porque admirava o que o princeps fazia e a época em que vivia? Ou porque lhe era necessária e conveniente essa atitude para alcançar a fama e, em última instância, sobreviver? 
O caminho que nos interessa deriva dessa investigação, mas não se centra em nenhuma dessas linhas. Partimos de uma evidência: Marcial, efectivamente, adula. Deste modo, o âmbito da nossa análise define-se como aquilo a que chamaremos a estratégia da adulação, isto é, a observação dos meios de que o poeta se serviu para conseguir um objectivo: o encómio de um momento - aquele em que vivia e escrevia - e o de quem, nesse momento, detinha o poder. Deixamos também de parte qualquer juízo de valor sobre os quinze anos do principado de Domiciano, aqueles durante os quais Marcial escreveu e publicou a maioria dos seus livros, tanto mais que, como é sabido, não é fácil traçar a bissectriz entre a visão laudatória que nos deram autores como, além de Marcial, Estácio, Sílio Itálico, até Quintiliano, e a perspectiva de condenação, tão parcial quanto o encómio, adoptada por escritores como Tácito, Plínio, Juvenal, Suetónio ou também Epicteto, Filóstrato, Díon Cássio. Não vem a despropósito lembrar que a leitura do principado de Domiciano foi feita, durante séculos, pelo prisma desfavorável que resulta dos textos destes autores, escritos em segurança após a morte de Domiciano, quando, para engrandecer os novos senhores de Roma, Nerva, Trajano, Adriano, havia que carregar o negro das tintas com que se pintava a tirania a que haviam posto fim.

Como se deduz do que é nosso objectivo, não aceitamos, pois, a linha de análise que julga entrever nos epigramas de Marcial uma condenação mais ou menos explícita, feita de modo irónico ${ }^{1}$ ou subtil, da política e da pessoa de cada um dos imperadores. Ainda em recente estudo, ${ }^{2}$ Hannah Fearnley procura descortinar no livro 10 uma atitude de demarcação e censura em relação a Trajano, ${ }^{3}$ que, a nosso ver, não existe: o que

${ }^{1}$ Leiam-se, por exemplo, os estudos de J. Garthwaite, "Martial, Book 6, on Domitian's Moral Censorship": Prudentia 22 (1990) 13-22; "The Panegyrics of Domitian in Martial Book 9": Ramus 22 (1993) 78-101; ou de T. Herrera Zapién, "Marcial, divinizador casi irónico de los Césares": Nova Tellus 2 (1984) 67-83.

2 "Reading the Imperial Revolution: Martial, Epigrams 10" in A. J. Boyle W. J. Dominik (eds.), Flavian Rome. Culture, Image, Text (Leiden - Boston, Brill, 2003) 613-635. O estudo procura ler o Livro 10 como aplicação prática da emphasis, segundo a definição de Quintiliano (Inst. Or. 9. 2. 64-5).

${ }^{3}$ De forma mais sucinta, 'lê' também, no Livro 9, duas áreas temáticas cuja descodificação «reveals Domitian's hypocrisy» (p. 621): «Domitian's moral legislation and his building program» (p. 620). 
o poeta faz, sem grande fulgor, é verdade, e sobretudo sem grande entusiasmo, é empreender uma tentativa, derradeira e infrutífera, como em breve saberia, de continuar a usufruir de apoio e algum reconhecimento após o assassínio de Domiciano. Ora, para o fazer, não lhe restava senão um caminho, aquele que se enquadrasse na nova orientação política e fizesse esquecer a adulação que dirigira a Domiciano, particularmente desenfreada nos últimos anos do seu principado, os mais terríveis, por sinal. Retracta-se, pois, de tudo quanto dissera e adianta que, enfim, chegou a Roma uma nova época de liberdade, justiça, clemência e concórdia, sob a tutela de Nerva e, depois, de Trajano. ${ }^{4}$

Sendo nosso objectivo descortinar o modo como Marcial desenvolveu a referida estratégia de adulação, deixaremos, todavia, de lado aquela que visa directamente a figura do imperador, traduzida por exemplo no louvor das suas qualidades, das vitórias militares obtidas, das medidas e leis promulgadas, da política de construções ou de jogos que empreendeu, em suma, a que resulta de uma escolha, que o poeta criteriosamente faz, dos acontecimentos e circunstâncias que considera importante enaltecer (ou denegrir), em campos tão diversos como o social, o militar, o político e religioso, o administrativo. ${ }^{5}$ Vamos, antes, centrar-nos numa outra forma de chegar ao princeps, indirecta, mas nem por isso menos eficaz: a adulação de personalidades que, por uma razão ou por outra, lhe são próximas.

Nos seus louvores, Marcial parece proceder segundo um esquema de círculos concêntricos que progressivamente se afastam, em termos de poder e influência, de um centro, obviamente ocupado pelos principes sob quem escreveu, Tito, Domiciano, Nerva e Trajano, num arco cronológico que vai de 80 , ano em que publicou o Liber de spectaculis sobre os jogos inaugurais do anfiteatro flávio, dados por Tito, até ao ano 101 / 102, data em que divulga a sua última recolha de epigramas, o Livro 12. É a esses quatro imperadores que o poeta se dirige preferencialmente, como resulta lógico do facto de viver numa sociedade organizada em pirâmide, onde todos dependem de alguém, excepto o princeps, e de ter de sobrevi-

${ }^{4}$ Cf. $11.2 ; 3 ; 4 ; 5 ; 7 ; 12.5$ (Nerva); 10. 6; 7; 34; 72; $12.8 ; 9$ (Trajano).

${ }^{5}$ Estes e outros aspectos, alguns dos quais retomados nesta comunicação, foram tratados na nossa tese de Doutoramento, $A$ adulatio em Marcial, apresentada à Faculdade de Letras da Universidade de Lisboa, e defendida em Outubro de 1993. 
ver num sistema político que, sendo de facto uma monarquia, faz com que a vida e a morte, o favor ou a desgraça, dependam tão-só da vontade ou do capricho desse princeps.

Durante o principado de Domiciano, sobre o qual incidirá a nossa análise, Marcial não enjeita a vantagem de adular ou evocar aqueles que, seguindo carreiras políticas ou militares de relevo, eram responsáveis pela concretização da política imperial, ou aqueles que, pela fortuna ou estatuto de que gozavam, pertenciam aos estratos político-sociais dominantes, apoiando e construindo aquela que Marcial diz ser a grandeza da época. Para só referirmos alguns exemplos mais notáveis e cuja identificação não suscita dúvidas, nos Epigramas há espaço para políticos e altos funcionários imperiais como Sílio Itálico, Plínio-o-Moço, Arrúncio Estela, Estertínio Avito, os irmãos Cúrvios, Lucano e Tulo, Cláudio Etrusco e seu pai, a rationibus de Tibério e dos imperadores que lhe sucederam, Licínio Sura, Antístio Rústico, Domício Apolinar, M. António Primo, Mécio Célere, legado na Hispânia Citerior, Istâncio Rufo, que veio a ser procônsul da Bética. Uns são patronos e amigos de Marcial. Outros, apenas patronos, efectivos ou desejados. A estes nomes juntam-se outros, mais ligados ao campo da arte, como Rabírio, o arquitecto que desenhou e construiu o fabuloso Palatium, ${ }^{6}$ ou da literatura, como Quintiliano, preceptor dos filhos adoptivos de Domiciano, ${ }^{7}$ ou Colino e Caro, ${ }^{8}$ premiados,

${ }^{6}$ Em 92. Rabírio é louvado porque percebeu que, para a majestade do princeps, só o palácio próprio de um deus seria adequado. Em 7. 56, o poeta dirige-se-lhe e realça a pietas (v. 1: "pia ... mente») com que concebeu a morada do deus vivo, como se fora um templo ou o próprio céu. Concluída a obra, Rabírio é esquecido e o foco vira-se para o próprio Palatium e quem o habita (8. 36) ou frequenta (8. 39). Mais tarde, morto Domiciano, Marcial recorda Rabírio, na $2^{\mathbf{a}}$ edição do Livro 10. Desta vez, porém, a pietas do arquitecto, que o poeta louva, tem outro objecto: o epigr. 71 é um epitáfio poético de seus amados pais, unidos na morte como sempre tinham estado em vida.

7 Em 2. 90, 1-2, ao vocativo, Quintiliane, o poeta acrescenta dois apostos: «uagae moderator summe iuuentae / gloria Romanae ... togae», que apontam para a sua condição de orador, advogado, escritor e educador de relevo.

${ }^{8}$ Colino sagrou-se vencedor no primeiro ludus Capitolinus, celebrado em 86 (cf. 4. 54, 2: «prima cingere fronde»); Caro triunfou nos ludi Albani: a coroa de folhas de oliveira que então recebeu como símbolo da sua vitória colocou-a no busto que possuía do imperador, gesto que Marcial evoca (9. 23; 24). 
respectivamente, nos ludi Capitolini ${ }^{9}$ e nos ludi Albani, jogos instituídos pelo princeps.

Marcial dá, porém, atenção especial aos membros da familia de Domiciano, quer os que a ela pertenciam por laços de sangue, quer os que nela se integravam por serem libertos do imperador. Entre os parentes de sangue, sublinhe-se a evocação de quatro diui, todos eles chamados a enaltecer a pietas do imperador mas também, segundo a nossa leitura, para recordar alguns dos seus afectos mais profundos. Estão neste caso Júlia, filha de Tito, a sobrinha de quem as fontes adversas aos Flávios dizem ter mantido com o tio uma relação incestuosa a que a morte veio pôr fim, no seguimento de um aborto que o princeps a teria obrigado a fazer; 10 e o filho que Domiciano teve de Domícia Longina, sua mulher, e que morreu ainda criança, em 73, isto é, vários anos antes do momento em que o poeta se refere a ele. ${ }^{11}$ Quanto ao pai, Vespasiano, e ao irmão,

9 Também o tragediógrafo Mémore ganhou um prémio num agon Capitolinus, vitória que suscita o louvor de Marcial em 11. 9. Mémore era irmão de Turno, poeta satírico que, com a sua crítica acerba ao tempo dos Júlios-Cláudios, terá apoiado a política de Domiciano, pelo que não é de admirar o apreço que Marcial lhe demonstra em 7.97, 8 e 11. 10.

10 Plin., Epist. 4. 11. 6; Suet., Dom. 22. 2; Philost., Vita Apoll. 7. 7; Juv. 2. 32; Díon 67. 3. Para afastar do caminho a presença incómoda do marido de Júlia, Domiciano mandou-o executar, sob acusação de que conspirara contra ele. Júlia surge em três epigramas: 6. 3; 13; 9. 1. Em 6. 3, poema que integra um livro publicado em 90, pouco tempo após a morte de Júlia, ocorrida em 89, ela é assimilada à Parca que, força benfazeja, fiará um longo fio da vida para um herdeiro de Domiciano que todos esperam que não demore a nascer. Em 6. 13, écfrasis de uma escultura que a representava identificada a Vénus, Marcial insiste na evocação da sua beleza e doçura: mas o facto de ter com ela o cinto da deusa, a cujo poder de sedução nenhum ser, mortal ou divino, resistia, parece evocar subtilmente o sentimento que Júlia despertou no Tonante de Roma. Em 9. 1, 6 ss., Marcial faz depender a eternidade da glória da gens Flauia, entre outras circunstâncias, da continuação do culto prestado pelas matronas romanas ao «diuae dulce Iuliae numen» (v. 7).

${ }^{11}$ Em 4.3 e 9. 86. No primeiro epigrama, a imagem do filho, divinizado, serve ao poeta para realçar a coragem física de Domiciano: impávido perante a chuva e a neve que o ensopam e enregelam, o princeps sorri, habituado como está aos rigores das paragens onde combate e domina os povos germânicos, sem se aborrecer com Júpiter, que preside às condições climatéricas. Mas o poeta tem 
Tito, o valor militar de ambos serve sobretudo para engrandecer o de Domiciano, como acontece por exemplo em 2. 2, 5-6, onde o poeta realça o facto de o princeps ter celebrado, sozinho, o triunfo sobre os Catos, em 83, enquanto o pai e o irmão dividiram o triunfo sobre os Judeus. ${ }^{12}$

Quanto aos libertos, Marcial escolhe aqueles que, dentro do Palatium, tinham funções relacionadas com o tratamento e atendimento do princeps, pois, naturalmente, vê-os como essenciais no processo de adulação que empreende: a convivência diária com o imperador e a intimidade que daí advinha não só lhe permitem elogiar as qualidades dos que rodeiam o senhor de Roma, como também constituem factores que poderão garantir-lhe acesso ao favor de que ambicionava gozar. Assim sendo, invoca-os como intermediários para abordar o princeps ou, simplesmente, como meio de amenizar a ousadia do que diz, requer ou sugere.

De entre os libertos a quem presta homenagem, o mais importante é Parténio, o cubicularius de Domiciano, funções que o poeta realça logo no primeiro epigrama em que se lhe refere, ${ }^{13}$ e lhe interessam sobremaneira para invocar protecção e divulgação da sua obra junto do princeps. Marcial louva-o ainda pelo incomparável valor poético e pela insuperável integridade do seu carácter. ${ }^{14}$ Ora, da inspiração poética, nada podemos

outra interpretação, que revela no último verso: deve ser o menino que as envia, lá de cima, em jeito de brincadeira com o pai (v. 8: «suspicor has pueri Caesaris esse niues»). Em 9. 86, Marcial dá, a Sílio Itálico, que chorava a perda recente de um filho de futuro promissor, alguns exemplos (divinos) de pais que perderam filhos: Apolo, que viu morrer Lino; Calíope, mãe de Orfeu; o Júpiter do Olimpo e o Júpiter do Palatino: àquele roubou Láquesis Sarpédon, a este, o menino desaparecido em 73.

12 Além disso, Domiciano é apresentado, no epigrama, como o único herói que repete a glória militar (nos vv. 3-4, Marcial alude à sua intervenção, com apenas 18 anos, contra o inimigo germânico), colocando-o ainda no culminar de uma gradação ascendente de valorosos generais (Cipião Africano, Metelo Crético, Vespasiano e Tito) que mereceram a honra de juntar aos nomes títulos militares.

13 4. 45, 2: «Palatinus ... Parthenius». O epigrama celebra o aniversário do filho de Parténio, que acabava de completar cinco anos. Marcial associa-se ao voto de que os deuses lhe dêem uma vida longa e plena.

14 4. 45; 5. 6; 8. 28; 9. 49; 11. 1 ; 12. 11. Este último epigrama, publicado no livro que escreveu já na Hispânia, c. de 101, é evidentemente um dos recuperados pelo poeta para completar a magra recolha que compusera para aceder ao pedido de Terêncio Prisco, seu amigo e protector dos sombrios dias do fim da sua vida. 
avaliar, pois nem um verso chegou até nós, transparecendo dos passos em que tal qualidade lhe é atribuída um jeito de lugar-comum, de topos de panegírico. Quanto ao carácter, podemos pelo menos pronunciar-nos acerca da lealdade para com Domiciano, já que Parténio foi um dos elementos do grupo que planeou e executou o assassínio do imperador. Suetónio (Dom. 16. 17) mostra-o, aproveitando-se justamente da confiança que o princeps nele depositava, bem como do conhecimento do seu carácter suspeitoso e persecutório, para o levar a admitir no quarto alguém que, segundo disse, lhe trazia uma informação grave e urgente. Convencido de que seriam provas de mais uma conspiração contra a sua pessoa, Domiciano recebeu Estéfano, o assassino que desferiu o primeiro golpe. ${ }^{15}$

Morto o tirano, Parténio ficou incólume e confirmado na posição junto de Nerva. Por isso Marcial o invoca para tentar acolher-se à protecção do novo imperador, fazendo esquecer a adulação que outrora dirigira a Domiciano. Realça agora apenas o valor da sua arte, insinuando a missão de propaganda que, evidentemente, está disposto a assumir também em abono de Nerva. O favor de Parténio, porém, não durou muito. $O$ velho imperador pretendia perdoar a todos os que haviam participado no assassínio de Domiciano: movia-o uma intenção pacificadora de ódios vivíssimos, mas decerto também o reconhecimento, quer do facto de que lhes devia o imperium, quer talvez de que não há que dar castigo a quem liberta a pátria de um tirano. No entanto, foi constrangido a ceder às pressões da guarda pretoriana, que se mantivera fiel à memória, ainda que damnata, do princeps morto. Relutante, viu ultrapassada a sua autoridade e os principais implicados no homicídio de Domiciano foram justiçados em $97 .{ }^{16}$ Parténio sofreu morte humilhante ${ }^{17}$ e o imperador teve de

15 Domiciano estava sozinho e não pôde, obviamente, defender-se, tanto mais que logo acorreram os restantes conspiradores, entre os quais se encontrava um liberto de Parténio. Para esconder a arma, Estéfano andara, vários dias antes, com um braço enfaixado, simulando ferida: era dentro das ligaduras que ia a arma no dia do assassínio. Díon (67. 17) torna ainda mais tenebrosa a participação de Parténio neste homicídio. Tentando defender-se, já mortalmente atingido, Domiciano procurou um punhal que sempre guardara, escondido no seu leito. Mas a lâmina fora arrancada pelo cubicularius, e Domiciano só encontrou o cabo.

${ }^{16}$ Ps. Aur. Vict., Epit. 12. 6-8.

17 Ps. Aur. Vict., Epit. 12. 8: «sed milites neglecto principe ... Parthenium uero demptis prius genitalibus et in os coniectis iugulauere...» 
agradecer publicamente a quem o livrara de tão execrandas figuras. ${ }^{18}$ Marcial perdia, assim, uma das personagens em quem mais tinha apostado para conseguir a protecção imperial, e essa perda era tanto mais grave, quanto acontecia no momento em que ele tentava associar os seus louvores à nova dinastia e à nova ordem política, demarcando-se do que anteriormente fizera.

Eufemo, liberto de origem grega que desempenhava funções também de mordomo de Domiciano, é invocado em 4.8. Por seu intermédio, Marcial presta ao princeps a sua homenagem e expressa o desejo de que ele o leia e proteja. O epigrama mostra bem quais são os objectivos do poeta e em que medida Eufemo lhe é necessário. Se louva e engrandece o princeps, que apresenta divino, moderado, em toda a sua bonomia e autoridade,$^{19} \mathrm{em}$ troca, espera protecção. No benefício, abrange Eufemo, cuja situação privilegiada no Palatium sublinha, esperando que ele apresente os Epigramas, no momento azado, ao imperador. As funções do liberto são, nesse sentido, uma mais-valia: Marcial não ousa desejar a atenção do princeps nas matutinas horas em que ele se ocupa de assuntos sérios e de peso. Ora, sendo Eufemo seu tricliniarcha, está junto dele nas horas de lazer, prepara-lhe a cena, serve-lhe a ambrósia e o néctar de que se alimenta, assiste-o no momento em que descansa. Assim sendo, e como se aceita que Domiciano é deus, o liberto assume um papel que se assemelha ao do sacerdote de um culto, entidade que faz a ponte entre os simples humanos e a divindade. A verdadeira relação que se deseja estabelecer é, no entanto, simplesmente entre Marcial (nostra Thalia) e Domiciano (Iuppiter), entre o talento poético e o poder. Eufemo não é, assim, mais que um instrumento, um degrau, um trampolim.

No mesmo livro em que se dirige a Eufemo - e também naquele em que refere Parténio pela primeira vez - Marcial aposta em outra figura próxima de Domiciano, Sigero, que cita, sem se lhe dirigir, associado justamente a Parténio, cujas funções secundaria: poderosos ministri,

${ }^{18}$ Ps. Aur. Vict., Epit. 12. 8: «qui [Caspério Eliano] scelere tam truci insolentior Neruam compulit referre apud populum gratias militibus, quia pessimos nefandosque omnium mortalium peremissent».

${ }^{19}$ A relação entre o poder absoluto que detém e a parcimónia e moderação de que dá mostras é traduzida de forma especial no v. 10, quando Marcial evoca Domiciano que, com a sua ingens manus, segura pocula parca. Aliteração, antítese, metonímia, tudo sublinha a coexistência dessas duas qualidades. 
ambos representam, por antonomásia, aqueles que importa conhecer, ${ }^{20}$ dado o lugar que detêm no universo restrito dos que vivem e convivem com o senhor de Roma. Ora, segundo Díon (67. 15. 1), também Sigero estava entre os amici e liberti que planearam e executaram o homicídio de Domiciano.

No Livro 5, epigrama 5, Marcial alarga a esfera da adulação a Sexto, outro liberto do princeps, seu secretário e bibliotecário. Torna-se, assim, fortemente indicado para introduzir o poeta no Palatium, ${ }^{21}$ tanto mais que este lhe atribui, também a ele, dotes oratórios de relevo.22 O lugar excepcional ocupado por este a studiis na familia principis parece ainda confirmado pelo facto de Sexto ser o primeiro destinatário a cuja protecção Marcial se confia, logo após Domiciano, a quem o Livro 5 é dedicado e que é alvo do encómio dos três primeiros epigramas da recolha. Curioso é notar que, no poema imediatamente a seguir àquele que visa Sexto, Marcial dirige-se a Parténio, a quem pede que apresente o livro de epigramas, sem nada dizer, a Domiciano, certo como está de que a apetência do princeps por tudo o que é inspirado pelas musas o levará a pegar nele e a lê-lo. ${ }^{23} \mathrm{~A}$ atribuição, na arquitectura do livro, de um deter-

${ }^{20} \mathrm{Ou}$, como é o caso do 'Afro' de 4. 78, dizer que se conhecem (vv. 7-8), ainda que seja para se dar ares de importante. Note-se, todavia, que o facto de Marcial se referir a Sigero desta forma indirecta e de não voltar a nomeá-lo, pode indiciar que esta foi uma tentativa falhada de conseguir aproximar-se de mais um patrono que pudesse valer-lhe apoio e reconhecimento junto de Domiciano.

${ }^{21}$ Veja-se o efeito conseguido com o parêntesis dos vv. 3-4: depois da apóstrofe ao liberto, Sexte, seguida de dois apostos («Palatinae cultor facunde Mineruae / ingenio frueris qui propiore dei»), o poeta interrompe o que diz para salientar a intimidade de Sexto com o imperador, reconhecendo-lhe o privilégio de assistir ao nascimento das imortais obras de Domiciano e de usufruir de perto da inspiração do deus do Palatino. Ao apontar para tão soberba regalia, Marcial não só satisfaz o amor-próprio do minister imperial, como o predispõe a seu favor na tarefa de incluir este novo livro na biblioteca do Palatium.

$22 \mathrm{O}$ adjectivo facundus caracteriza, entre muitas outras, três das figuras próximas de Domiciano de que aqui nos ocupamos: Sexto $(5.5,1)$; Régulo (6. 64, 11) e Parténio $(8.28,1)$.

${ }^{23}$ No caso deste epigrama, 5. 6, a 'cadeia' de intermediários inclui um primeiro, divino, que são as Musas; e um segundo, humano, que é Parténio. O objectivo (ser lido no Palatium) e os meios (louvor de Parténio e de Domiciano) são os de sempre, tal como os votos que expressa ao liberto imperial (entre eles, 
minado lugar aos epigramas revela-se, assim, uma outra forma de Marcial dar relevo às personagens que considera fulcrais na obtenção de apoio.

A leitura do epigrama dedicado a Sexto, porém, mostra um conjunto de processos que induzem o leitor à desejada conclusão de que o destinatário da lisonja é Domiciano. Além da alusão ao culto especial que o princeps votava a Minerva, Marcial insiste no louvor dos dotes poéticos do imperador, recordando-lhe o ingenium (v. 2) e o poema épico sobre o combate do Capitólio, em Dezembro de 69, entre as tropas de Vitélio e as que apoiavam Vespasiano. Repare-se que, ao rogar a Sexto que reserve um lugar na biblioteca do Palatino para os Epigramas, Marcial deseja que ele os coloque na 'secção' adequada, junto das obras de Catulo, Domício Marso e Albinovano Pedão, seus modelos na arte epigramática; e esse é o pretexto para sugerir que, ao lado dos caelestia carmina sobre a guerra do Capitólio, nada esteja senão o «grande cothurnati ... Maronis opus» (vv. 7-8). Isto é: enquanto a obra do mais sublime poeta épico é apenas grandiosa, os poemas de Domiciano são divinos, o que estabelece uma seriação em termos de valor, de que Vergílio sai a perder. Ora, a essência divina do princeps já fora garantida, quando, no v. 2, se disse que Sexto usufruía do ingenium de um deus, palavra que, para ganhar realce, fecha o pentâmetro. ${ }^{24}$ Se em seguida virmos que Marcial se refere a Domiciano, no v. 3, como dominus, título que aparece sublinhado pela posição métrica - entre a cesura pentemímere e a heftemímere do hexâmetro - teremos completa a designação dominus et deus que, em 89, justamente o ano em que o Livro 5 foi editado, o princeps ordenou que fosse, a partir daí, a única forma por que se lhe dirigissem, quer por escrito, quer oralmente. A fórmula de tratamento aqui sugerida é a que o poeta explicita no v. 1 («Edictum domini deique nostri») do epigr. 8 do mesmo livro, isto é, três epigramas depois deste. Por fim, em técnica de uariatio que lhe é comum, Marcial refere-se ao imperador por mais um título, o de $d u x$, no v. $4 .{ }^{25}$ Assim

que morra de velhice e sempre sob o divino princeps: v. 4). A presença das Musas, por isso, apenas reforça o que une os quatro elementos da cadeia: a inspiração poética.

${ }^{24}$ A primeira é ingenio; isto é, o pentâmetro abre e fecha com as palavras que traduzem as duas características louvadas no epigrama: o valor poético, a essência divina.

${ }^{25}$ Também a métrica o coloca em realce: ducis surge antes da cesura do pentâmetro. 
resulta completo o quadro da dependência e do encómio: Domiciano é deus, senhor de todos os que a ele se submetem como escravos, chefe militar invencível, poeta a quem a própria Minerva dá inspiração.

Outro liberto escolhido foi Entelo, a libellis de Domiciano, de quem Díon diz (67. 15. 1) ter também sido um dos seus assassinos. Marcial, porém, não lhe refere o privilégio das funções, escolhendo desta feita, para alvo do encómio, as maravilhas da técnica que soube aplicar a uma estufa com que dotou a sua vinha e que lhe permitia produção em pleno inverno. ${ }^{26}$

Mais significativo se apresenta o caso de Flávio Eárino, escanção de Domiciano e seu puer delicatus, entre todos preferido. A atenção de Marcial era inevitável. ${ }^{27}$ No Livro 9, publicado pelo ano 94, dedica-lhe seis epigramas, decerto no momento em que o jovem atingia o auge do favor do princeps. Essas composições constituem um ciclo, ${ }^{28}$ pois ocupam-se de um tema uno, encontrando-se, porém, entre os epigramas que o desenvolvem, variações formais, por exemplo na utilização de metros diferentes ou na diversificação das apóstrofes, mas também na multiplicidade de aspectos e pormenores registados. Assim, este ciclo gira em torno de dois motivos distintos: o nome do favorito, aliado à sua beleza e graça $(11 ; 12 ; 13)$; a consagração do cabelo e de um espelho do jovem, enviados, como oferenda a Esculápio, para um templo de Pérgamo, cidade de onde ele era natural $(16 ; 17 ; 36)$. O epigrama 11 , em hendecassílabos falécios, dá início ao ciclo e lança os dados da questão: Marcial

${ }^{26}$ 8. 68. Note-se que se trata de um epigrama em que a apóstrofe se dirige ao próprio Entelo, sem qualquer alusão ou sugestão da presença de Domiciano, e sobre um tema que pressupõe um conhecimento directo da estufa por parte de Marcial. Com tais processos consegue o poeta traduzir a intimidade que o liga à influente personagem.

${ }^{27}$ Como aconteceu com Estácio, movido por idênticos interesses (Silu. 3. 4). Por ele sabemos que Eárino era spado: fora castrado antes do edicto de Domiciano que proibia tal prática (Suet., Dom. 7. 1). É provável que tenha sido o próprio Domiciano a sugerir, a quantos aspiravam ao seu favor, a homenagem poética de Eárino.

28 Sobre os 'ciclos' como forma de composição nos Epigramas, v. K. Barwick, "Zyklen bei Martial in den kleinen Gedichten des Catull": Philologus 102 (1958) 284-318; e O. Weinreich, Studien zu Martial (Stuttgart, Tübinger Beiträge zur Altertumwissenschaft, 1928). 
quer louvar Earinus mas não the pode pronunciar o nome por razões métricas; ${ }^{29}$ por isso recorre a apóstrofes ao nomen (vv. 1 e 10) e à syllaba contumax (v. 12) que lhe vedam a invocação directa, e sugere o nome pela alusão ao fascínio que o jovem exerce sobre quantos o vêem, poder que um eco de Catulo sublinha. ${ }^{30}$ Neste epigrama, Eárino é referido na $3^{\mathrm{a}}$ pessoa e Domiciano, que logo adivinhamos ser o principal destinatário do ciclo, não é sequer nomeado. Os laços que unem Eárino e o princeps, mas também as funções que aquele ocupava no Palatium, sugerem-se pela evocação de Ganimedes, o escanção do pai dos deuses, o que, na perspectiva da adulação, resulta sobretudo em equiparar Domiciano a Júpiter. ${ }^{31}$ Ao facto de Eárino ser castrado, ${ }^{32}$ alude o poeta pela referência a Átis, o amado puer da deusa Cíbele, o que, como se vê, volta a identificar Domiciano, mesmo por via dos seus amores, com uma divindade.

No epigr. 12, em dísticos elegíacos, a aproximação concretiza-se: a apóstrofe é ao próprio Eárino, a quem o poeta garante que só o seu nome - i. e.: ele - é digno de morar «in Caesaris domo» (v. 8). É este verso que introduz no ciclo, de forma explícita, a referência ao dominus e à ligação entre ambos. No epigr. 13, também em dístico elegíaco, é o próprio puer quem fala: Marcial apaga-se e Domiciano é como que esquecido. O objectivo é, de novo, sugerir o nome e o que ele traduz da frescura e beleza que distingue o seu portador, desta vez por meio de uma espécie de charada em que se joga com a relação do nome com o substantivo grego ê $\alpha \rho$, primavera.

No epigr. 16 introduz-se o segundo tópico do ciclo, sem deixar de estabelecer a ponte com o aspecto dominante nos três primeiros poemas, o que é feito pelo v. 16 («nomine qui signat tempora uerna suo»). Agora, em três dísticos elegíacos, o poeta concentra a atenção sobre as oferendas, o espelho e os cabelos recém-cortados. Eárino é referido na $3^{\mathrm{a}}$ pessoa, tal

${ }^{29}$ Em nenhum dos metros que usa nos epigramas cabe a quantidade (breve) da primeira sílaba de Earinus.

30 9.11: «respondent Veneres Cupidinesque...» Cf. Catulo 3. 1.

${ }^{31}$ Note-se que o v. 7 («et qui pocula temperat Tonanti») deixa pairar a ambiguidade sobre a identificação do Tonans aí referido.

32 Domiciano, todavia, proibiu a castração de jovens e diminuiu o preço dos eunucos que se encontravam à venda, como forma de dissuadir a continuação da prática (cf. Suet., Dom. 7.1; Díon 67. 3; Am. Marc. 18. 4. 5). Marcial evoca a determinação em $2.60 ; 6.2 ; 9.5 ; 7$. 
como Domiciano, mas sublinha-se de novo a relação que os une (v. 3: «ille puer tota domino gratissimus aula») $)^{33}$ e a vantagem do jovem sobre Ganimedes. $^{34} \mathrm{Em} \mathrm{17}$, também em dísticos elegíacos, a apóstrofe dirige-se a Esculápio, deus a quem se realça o valor e o significado das oferendas, pedindo-lhe em troca o que, interpreta Marcial, Domiciano mais deseja: «Tu iunenale decus serua, ne pulchrior ille / in longa fuerit quam breuiore coma» (vv. 7-8). Isto é: que ele fique belo e de aspecto juvenil, para que o seu dominus ${ }^{35}$ possa continuar a tê-lo como favorito. Finalmente, no epigr. 36, de novo em dísticos elegíacos, Marcial ascende à esfera do Olimpo e surpreende Júpiter e Ganimedes em diálogo: são agora eles que reconhecem a superioridade de Domiciano e Eárino e confirmam o afecto que os une. Como nota mais evidente da adulação, estabelece-se, no v. 2, uma curiosa hierarquia, quando se diz que Ganimedes é «alterius gaudia nota Iouis»: o Júpiter do céu passa para segundo plano perante o deus de Roma, Domiciano. Em face do pedido do seu puer que, como Eárino, deseja cortar o cabelo, o que equivale a sair da sua alçada afectiva e sexual, não admira, pois, que Júpiter, de categoria inferior à do divino princeps, tenha que lho recusar: ele não tem, como Domiciano, mil jovens celestiais a servi-lo, por isso, se Ganimedes assumir a sua entrada na idade adulta, não terá quem lhe sirva o néctar. Como se vê, não é Eárino quem Marcial adula: no fim do ciclo, ele é um entre mil, ${ }^{36}$ apenas se distingue, num dado momento, por ser objecto dos amores do princeps. É este que se louva, na sua riqueza e poder absoluto, na sua natureza que se assegura divina.

O poeta visa ainda outro grupo de colaboradores próximos de Domiciano, constituído pelos delatores. O exemplo mais expressivo é o de Marco Aquílio Régulo, de quem nos deixou um retrato em tudo antagónico àquele que outras fontes, como Plínio e Tácito, traçaram. Para

33 A escansão do hexâmetro é sugestiva: puer está antes da cesura triemímere; domino entre as cesuras pentemímere e heftemímere.

${ }^{34}$ Cf. v. 6: Pérgamo não preferiria possuir, em vez dos cabelos de Eárino, os de Ganimedes.

35 Veja-se, uma vez mais, o realce dado pelo facto de, no v. 3, domino estar entre as cesuras pentemímere e heftemímere, enquanto, no v. 4, o pentâmetro fecha com o substantivo puer.

36 Díon confirma o pendor de Domiciano por jovenzinhos, gosto que acumulava com o que tinha pelo comércio carnal com as mulheres (67. 6.3). 
Marcial, ${ }^{37}$ ele é um ser de excepção que os amigos idolatram e a providência protege, cujo carácter sem mácula se ilustra pela vasta cultura e inexcedível talento. Ele é também o advogado que se empenha somente em defender os inocentes, que desconhece o insucesso e conquista o reconhecimento público, circunstância a que não é alheio o facto de ser modelo insuperável de eloquência, vivo retrato do defunto Cícero. Ora, as cartas de Plínio revelam-nos um outro Régulo, em cuja vida e carácter nada existia de honesto ou justo. Basta recordar que só quando Régulo morreu Plínio teve ensejo de dizer alguma coisa de bom acerca dele, afirmando: «bene fecit Regulus quod est mortuus».38 Por ele sabemos que foi acusador e delator, desde os tempos de Nero, ${ }^{39}$ sem nunca dar tréguas às suas vítimas, nem mesmo quando morriam. ${ }^{40}$ Acusava por prazer e cobiça, temido e odiado por muitos, mas nada o atingia, seguro que estava da protecção imperial. Apenas quando Domiciano foi morto se sentiu ameaçado. ${ }^{41}$ Nada, porém, lhe aconteceu, e conservou o favor e o lugar no senado. Captava, além disso, as boas graças de moribundos abastados, o que amiúde lhe valeu ser contemplado em testamentos. ${ }^{42}$ Não é assim que Marcial o pinta: além de louvar, como vimos, as suas inúmeras qualidades, aproveita todos os pretextos para o referir, deixando transparecer, em diálogos e comentários, a intimidade entre ambos. Régulo, todavia, parece não ter sido muito generoso no cumpri-

37 Para o retrato de Régulo em Marcial e das relações entre eles, v. 1. 12; 82; $111 ; 2.74,2-3 ; 93,3 ; 4.16,6 ; 5.10,1-3 ; 21,1 ; 28,6 ; 63,4 ; 6.38 ; 64,11 ; 7.16 ; 31$.

38 Epist. 6. 2, 4. Além disso, aponta como positivo o facto de ele ter conseguido obter, para si e para os que advogavam a seu lado, dispensa das limitações de tempo nas intervenções (§3).

${ }^{39}$ Epist. 1. 5, 3. De Nero recebeu protecção e a dignidade de um sacerdócio (Tác., Hist. 4. 42, 6).

40 Como aconteceu com Aruleno Rústico, a quem continuou a chamar «Stoicorum simia» (Plin., Epist. 1. 5, 2), e com Herénio Senecião.

${ }^{41}$ Plin., Epist. 1. 5, 1: «Vidistine quemquam M. Regulo timidiorem, humiliorem post Domitiani mortem?(...) Coepit uereri...».

${ }^{42} \mathrm{Na}$ Epist. 2. 20, Plínio narra três desses episódios. E, em 4. 2, 2, revela que emancipou o filho para que este pudesse receber a herança da mãe, que ele usou depois em proveito próprio. Mais tarde, quando o jovem morreu, Plínio duvidou de que as manifestações enlouquecidas de dor fossem, da parte de Régulo, mais do que simples teatro (4. 2, 4: «nec dolor erat ille, sed ostentatio doloris»). 
mento dos deveres de patrono, já que, em 7. 31, a relação suspende-se: depois de uma última tentativa formal de encómio, em que associa à figura do homenageado a imagem da excelência da esposa e da prometedora virtude e inteligência do filhito de três anos (6. 38), o tom de Marcial torna-se quase impertinente..$^{43} \mathrm{E}$, uma vez que "aera domi non sunt» (7. 16, 1), evidentemente por falha de Régulo que lhe devia assistência e protecção, o poeta sugere-lhe que compre de volta os presentes que outrora lhe ofereceu. Marcial desiste, assim, de se acolher à sombra de tão notável personagem.

Sobre um outro nome, dos louvados por Marcial, pesa a suspeita de que tenha sido delator influente junto de Domiciano. ${ }^{44}$ Trata-se de Latino, actor e talvez também autor de mimos, género dramático tão ao gosto dos Romanos. A par dos gladiadores e dos aurigas, os mimos - e os pantomimos - eram ídolos populares que conquistavam fama e dinheiro. Foi o caso de Latino, a quem o princeps distinguia com o seu favor. ${ }^{45}$ Ora, à primeira vista, tal protecção parece estranha, já que Domiciano se fizera nomear censor perpetuus e fustigava, com leis e edictos, todos os desvios da austera moralidade e dos rectos costumes. ${ }^{46}$ Marcial, porém, encontra forma de explicar essa aparente contradição. Entre os elogios que faz a

43 7. 31, 7: «O quam, Regule, diligenter erras!» Marcial desengana Régulo: todos os presentes que lhe envia vêm, não da sua quintinha suburbana, mas dos mercados de Roma.

${ }^{44}$ É quase certo que, nos Epigramas, encontramos alusão a outros delatores: Bébio Massa (12. 28, 2) e Métio Caro (12. 25, 5), ambos acusadores, entre muitos outros, do estóico Herénio Senecião, ambos justiçados no tempo de Nerva. Caro seria ainda aquele que, segundo conta Plínio (Epist. 7. 27, 14), preparava a sua desgraça, em 96, quando Domiciano foi assassinado. Além destes, em 4. 54, 7 e 12. 36, 9, Marcial deve referir-se a Víbio Crispo, cuja enorme riqueza, a que o poeta alude, foi conseguida sobretudo como fruto da delação. Depois de carreira política de relevo, morreu, octogenário e sem castigo, antes do tirano.

45 Suet., Dom. 15. 10; Juv. 1. 35-36; shol. ad Iиu. 4. 53.

${ }^{46}$ Legislou, também, contra os actores de mimos, que foram proibidos de se exibirem nos teatros públicos, ficando confinados aos teatros privados e às representações em casa de particulares (Suet., Dom. 7. 1: «interdixit histrionibus scaenam»). Tê-lo-á feito, mais que pela imoralidade dos textos, pelas alusões políticas adversas que neles se faziam. É a opinião de H. Bardon, Les empereurs et les lettres latines d'Auguste à Hadrien (Paris, Les Belles Lettres, 1968') 330. 
Latino, deixa bem claro, em 9. 28, ${ }^{47}$ que o mimo levava vida proba, como convinha a quem com orgulho se assumia famulus (v. 10) do imperador. No entanto, em 1. 4, Latino é invocado, a par de Tímele, dançarina ou actriz de mimos, como intérprete dos gostos mais ligeiros de Domiciano. ${ }^{48}$ É por isso que ambos se tornam pretexto para Marcial pedir ao princeps que encare com bonomia a sua musa brejeira e inofensiva, assegurando que «lasciua est nobis pagina, uita proba» (v. 8).

Crispino é outro dos protegidos e amigos de Domiciano de quem Marcial dá uma imagem diferente da que outras fontes consagraram. Perante a sua figura, objecto das mais acerbas críticas e da mais viva repulsa, confessa Juvenal que «difficile est saturam non scribere». ${ }^{49}$ Nos dois epigramas em que Marcial o refere, houve já quem visse marcas mais ou menos disfarçadas de ironia, que afinava o tom pelo diapasão de Juvenal. ${ }^{50}$ Assim sendo, e uma vez que não lhe podia interessar pôr a ridículo um dos favoritos de Domiciano - reserva que não travou Juvenal por razões cronológicas, se outras não tiver havido -, Marcial teria escolhido uma forma subtil ${ }^{51}$ de dizer que Crispino era um pretensioso elegante que deixou que lhe roubassem a requintada capa e que, ainda por cima, se julgava muito mais importante junto do princeps do que na realidade era, e por isso se gabava.

A leitura não nos parece credível: o poeta não iria escrever tal libelo contra a excentricidade e a vaidade balofa de um liberto da casa imperial, feito eques e alto funcionário do Palatium. Parece-nos, antes, que Marcial aproveitou, em 8. 48, um dos episódios do quotidiano de uma influente

47 O epigrama parece ser um epitáfio poético, ou então tratar-se-á de epígrafe para um busto de Latino.

48 Nos outros epigramas em que refere Latino (2. 72, 3-4; 5. 61, 11-12), Marcial desenha uma imagem bem pobre daqueles que seriam os seus processos de fazer rir: o mimo é apenas lembrado pelos sonoros e monumentais bofetões que dava ao seu estúpido parceiro, Panículo, espécie de palhaço pobre ou de bombo da festa que só alcança glória porque é associado ao favorito do imperador. V. também 3. 86, 1; 13. 2, 3.

${ }^{49}$ 1. 30. V. 1. 26-30; 4. 1-33; 108-109.

50 W. C. McDermott, "Ecce iterum Crispinus": Rivista Storica dell'Antichità 8 (1978) 117-122.

${ }^{51} \mathrm{Ou}$ ambígua: cf. J. Gérard, Juvénal et la réalité contemporaine (Paris, Les Belles Lettres, 1976) 26, 142. 
personagem para se insinuar um pouco mais na sua esfera de confiança e, em consequência lógica, se aproximar do próprio princeps. O acontecimento evocado, o roubo de uma abolla púrpura, deve ter dado tanto que falar que Marcial dele se faz eco, ${ }^{52}$ num poema que é uma bem-humorada invectiva contra quem surripiou a capa. Realçando a extrema elegância de Crispino, o poeta mostra que essa distinção é, afinal, o motivo pelo qual o ladrão não poderá esconder-se por muito tempo: ninguém consegue passar despercebido com tal veste, a ninguém ela assentará como a Crispino, ninguém é assaz garboso para a usar. Por isso sugere: se o larápio não quiser denunciar-se, melhor será que roube a toga, pois é menos vistosa.

Que não poderia ser de ironia o tom deste epigrama, mas antes de divertida homenagem à elegância de Crispino - rico como era, não devia sequer estar muito preocupado com o furto - prova-o o teor do outro poema em que Marcial se lhe refere, 7. 99. Aí, sublinha a proximidade existente entre Domiciano e Crispino, pois este pode permitir-lhe subir mais um degrau em direcção ao topo ambicionado, as boas graças do princeps. E enuncia, sem rodeios, o que espera dele: que, quando a sua poesia for lida no Palácio, diga umas palavras que mostrem em que medida essa poesia tem sido e pode continuar a ser útil à propaganda do principado de Domiciano. Em troca, formula os votos habituais: que Crispino mantenha o favor imperial e o amem tanto em Roma como em Mênfis, sua terra natal.53 Ora, observe-se que o pedido de Marcial de que interceda por ele nada tem de louvor para com Crispino. Sem dizer uma palavra sobre as suas eventuais qualidades, limita-se a tomá-lo como intermediário de quem se espera uma tarefa, claramente definida, de recomendação, ainda para mais junto de alguém que, assegura, já há muito conhece e aprecia os Epigramas. O poeta garante que isso lhe bastará e, à semelhança do que fez no epigrama 5. 6, dirigido a Parténio,

52 Mais tarde, Juvenal também lembra as suas «Tyriae lacernae» (1. 27) e chama-lhe «purpureus... scurra Palati» (4.31), na longa enumeração dos seus vícios e actos nefandos, que compreendiam o incesto com uma Vestal, adultérios, negócios escuros...

${ }^{53}$ De novo o que é louvor em Marcial se virá a transformar em vitupério, com Juvenal, que diz que «Crispinus, uerna Canopi» (1. 26), veio do Egipto para a capital, no tempo de Nero, vender peixe que apregoava «magna uoce» (4. 32); tornado eques por mercê de Domiciano, pertenceria ao consilium principis. 
confia-se a Domiciano: o seu gosto apurado dará o devido valor ao novo livro que acaba de sair, a sua clarividência há-de apreciar e acolher a sugestão do serviço de propaganda. O destinatário do poema é, portanto, o princeps, e o encómio é para ele que se traça. Mais do que a vénia à cultura e aos dotes intelectuais, o que interessa ao poeta é frisar a essência divina do imperador. Se, no v. 1, a optação «Sic placidum uideas semper, Crispine, Tonantem» não permite a interpretação unívoca de que este Tonans seja Domiciano - identificação que, em outros epigramas, é explícita $^{54}$-, no v. 4, a metonímia «sacra ... aure», que exprime o carácter divino ${ }^{55}$ e a atenção do princeps, avança mais um passo na direç̧ão do supremo encómio, aquele que surge na palavra que fecha o epigrama: deo. Domiciano é, simplesmente, deus. Um deus a quem Marcial presta culto, como lhe é devido.

Concluímos. Naquele que, na expressão feliz de Jean-Luc Hennig, era o 'carnet d'adresses'56 de Marcial, alguns nomes parecem ser mais importantes que outros, tendo em vista o objectivo primeiro da adulação, e esses são os que gozavam de uma maior proximidade do imperador, os que partilhavam da sua intimidade e, por isso, se encontravam em posição de o recomendar e proteger. O poeta faz uma abordagem sistemática e quase exaustiva dos ministri, pueri, amigos e conselheiros de Domiciano, ensaia todas as técnicas e experimenta todos os recursos, umas vezes com sucesso, outras em vão, tanto quanto podemos depreender da presença repetida ou do desaparecimento dos nomes a quem se dirige ou refere. No entanto, é um só o patrono que deseja tocar, um único o farol que deseja por guia: Domiciano. É nele que tudo aposta, dos mais leves elogios às mais servis louvaminhas, não hesitando em enaltecer todos os seus actos e determinações. Se até 96 a recompensa foi, sem dúvida, escassa, nesse ano do assassínio do último Flávio Marcial colheu os mais amargos frutos que a sua arte semeara. Obrigado a desdizer-se e a contradizer-se, empurrado para o limbo da fama e do reconhecimento, sem futuro e com o peso de um passado embaraçoso, a vida em Roma tornou-se-lhe agreste e revelou-se no mais fundo desencanto de trinta e quatro anos de fadigas e humilhações. Um último alento, o que a saudade fez

${ }^{54}$ V., por ex., 6. 10, 9; 7. 56, 4; 99, 1; 9. 39, 1; 65, 1; 86, 7 .

55 Realçado pela colocação do adjectivo sacra antes da cesura do pentâmetro.

${ }^{56}$ Martial (Paris, Fayard, 2003). Trata-se do título do capítulo que ocupa as pp.243-263. 
nascer, trouxe-o de volta à Hispânia. Aí, além da nostalgia de Roma e dos poucos amigos que deveras o foram, a par do deserto que o rancor e a inveja dos conterrâneos abriram em seu redor, Marcial encontrou, poucos anos depois, a morte. E se, volvidos 1900 anos, o celebramos, é sem dúvida porque, postos de lado juízos anacrónicos sobre a sua atitude perante o poder ou preconceitos morais obsoletos sobre a sua tão apontada amoralidade, sabemos reconhecer nos Epigramas a arte e o talento de um grande poeta. ${ }^{57}$

${ }^{57}$ Fazemos nossas as palavras de Pascal Quignard (Petit Traités. Paris, 1990),

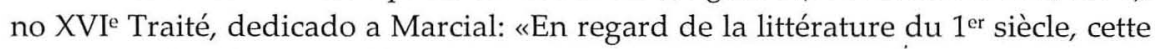
œuvre est la plus singulière qui soit. Elle ne contraste pas seulement par la précision de son lexique, par la haine de l'éloquence et de l'image, mais par la fermeté, la virulence de l'expression. Sorte de classicisme se faisant baroque à force de pureté. Tenait l'écrit pour rien. Art de la concretio.» 